\title{
IMPACT OF COVID-19 ON PERSONAL DEBT OF STREET VENDORS IN ROURKELA CITY: A LOGISTIC REGRESSION APPROACH
}

\author{
${ }^{1}$ Dibya Jyoti Suniani, ${ }^{2}$ Sandeep Kumar Patra, ${ }^{3}$ Bikash Sethy, ${ }^{4}$ Bhagaban Behera, \\ ${ }^{5}$ Jitamitra Mishra \\ ${ }^{1}$ P.G. Dept. of Commerce, Utkal University \\ ${ }^{2} P . G$. Dept. of Commerce, Utkal University \\ ${ }^{3}$ P.G. Dept. of Commerce, Utkal University \\ ${ }^{4}$ P.G. Dept. of Commerce, Utkal University \\ ${ }^{5}$ Dept. of Commerce, Govt. College, Rourkela
}

Article DOI: https://doi.org/10.36713/epra9528

DOI No: 10.36713/epra9528

\begin{abstract}
Undoubtedly covid-19 amidst lockdown has impacted millions of people across the world and various sectors altogether, the informal sectors are mainly affected as more than 60 percent of the workforce are engaged in the informal sector. Street vendors also fall under the category of informal sectors also got affected due to covid-19 and lockdown. The policy of work from home does not apply to them as they are the daily bread-earners, they spent on living what they have earned in a day. This paper focuses on studying the impact of Covid-19 on the personal debt of street vendors during the lockdown period. Using the Logistic regression technique, the impact of Covid-19 on the income of street vendors has been studied. The data mainly used in the study are primary and were collected from street vendors, fruits vendors, and vegetable sellers which were later analyzed by applying logistic regression and using E-views. It is found from the study that there is a significant impact of Covid-19 on increasing the personal debt level of the street vendors.
\end{abstract}

KEYWORDS: Covid-19 Pandemic, Lockdown, Street Vendors, Personal Debt

\section{INTRODUCTION}

Street vendors are an integral part of urban economies around the world, offering easy access to a wide range of goods and services in public spaces. they sell everything from vegetables to prepared food, from building material to garments and crafts, from consumer electronics to auto repair to a haircut (WIEGO). In March 2020, the government announced the strictest lockdown in the country, which came at the cost of the livelihood of millions of street vendors in the country (shah, 2020). Despite strict guidelines laid down by the government to

\section{LITERATURE REVIEW}

Husain et.al., (2015) tried to assess the socio-economic conditions and business issues of different street vendors.it also highlighted that poverty, lack of education, migration from rural areas \& large family size are the main driving force for carrying combat the covid-19 situation, the street vendor risks their lives to supply product, goods to the needy and also for their selfsurvival. The street vendors are fighting not only with covid-19 but also from hunger. They hardly had any financial backup to meet this pandemic by simply staying at home and depending on their saving thus it is impossible on their part to remain at home and stop their business. However, Odisha announced $29 \mathrm{cr}$ package for street vendors to be provided to each registered vendor amounting to Rs 3000 amid pandemic (mohanty, 2021)

out the street vending business. The author also discussed the socio-demographic and economic characteristics of street vendors followed by the problem faced by them. Further, the author suggested Bangladesh government strengthen the street vendors financially and can help in boosting the infrastructure development of the city so that their business is uninterrupted. 
Meher et.al. (2020) tried to explore the impact of lockdown on the livelihood of a street vendor. The author uses thematic analysis to analyze the data and find that lockdown impacted street vendors vulnerably. It is also found that during lockdown many other people entered into the street vending business which creates tough competition with the pre-existing vendors and many have taken a loan to sustain their business during lockdown period Deka (2020) impact of lockdown on street vendors and adverse effect on the livelihood. The author also studied the street vendor's views on street vending business activity post lockdown. The author for the study uses nonprobability convenient sampling from 50 street vendors and finds that many street vendors shut down their business during the covid-19 period as lack of sufficient capital compels them to leave the job and continue doing other jobs. He concluded by suggesting that financial help from the government is of great importance to revive the livelihood Vijayarani \& Selvam (2021) use convenience sampling method from 300 street vendors to compare pre and post covid-19 period to investigate the working lives of vendors in terms of financial and marketing conditions and also to assess the prospects of street vending in the context of Covid-19. The author applied the paired sample ttest and finds that there is a significant difference between pre and post covid-19 impact on street business but the livelihood conditions bring no change between both the pre and post covid19 period moreover government relief plans do not bring any change in their situation Ullah (2021) tried to explore the livelihood of street vendors during Covid-19 in Bangladesh. Using the purposive sampling technique, he makes a depth interview of 15 street vendors and finds that the Covid-19 lockdown is a significant burden for street vendors, leaving them no other options for earning. And during lockdown they spend total savings, borrow money from others and sell home furniture to fulfill their needs and demands Majithia (2020) highlighted the issue that arises to the street vendor during the covid19 period in Delhi and advised that though the registered street vendor are about 13100 out of roughly 300000 street vendors, TVC's must find the unregistered vendors by conducting a survey and make them registered to avail various government package directly into their bank account. The author also suggested the government take the step to ensure hygiene and social distancing at the site of vending Turner et.al, (2021) tried to examine how street vendors experienced and responded to the Covid-19. The author mainly focuses on rural to urban migrant street vendors for which 61 semis structured interview was used. He concluded that migrant vendors still continue with vending due to the household financial needs as the migrant vendors cannot have moved back to rural places due to the fear of facing social stigma.

\section{RESEARCH GAP}

The review of various studies on the impact of Covid-19 on street vendors revealed that there are population and empirical gap exists in the existing literatures becasue research on the impact of Covid-19 on the personal debt level of the street vendor in Rourkela city has not yet been attempted. The present study is an attempt to fill this research gap.

\section{RESEARCH OBJECTIVE}

The objective of this study is to find out the effect of Covid-19 on the personal debt of street vendors of Rourkela city.

\section{RESEARCH METHODOLOGY}

The present study was confined to the western part of Odisha that is Rourkela city. Primary data was collected for the study, for which a questionnaire is formed and was collected from 105 street vendors of Rourkela. A few of the respondents refused to take part in the survey. The convenience sampling technique is used to select the sample size from an undefined population size in Rourkela city. The first part of the questionnaire covers the demographic profile and the next part covers the impact of Covid-19. Primary data collected from 105 street vendors of Rourkela city it is found that 73 are male representing $69.5 \%$ of the total sample \& $30.5 \%$ of street vendors are female-headed which that is 32 females are also engaged in street vending jobs and are from all the age group and maximum respondent belongs to the category of 35-45 age group representing $31.4 \%$ of the total respondent. The household size showed that out of a total of 105 respondents 52 members had a family size between 4 to 6 members $\&$ all the members are fully dependent on the street vending job as their only source of livelihood. In the same way, the education profile of respondents depicts $36.2 \%$ of the street vendors i.e. 38 respondents have no primary education and are conducting their business without any literacy \& in the same way 29 and 32 street vendors have studied up to primary and upper primary education respectively. With regards to daily income, 79 street vendors had a daily income of Rs 500-700 and only 4 respondents earned above 2000 i.e. $3.8 \%$. The present study aims to study the effect of Covid-19 on the personal debt level of street vendors and also examine the ways adopted to tackle economic vulnerability during the Covid-19 period. The respondents were asked whether the personal debt is increased or not which is our dependent variable this is the prime reason for selecting logistic regression to analyze the data using E-Views software out of various statistical models as for binary or nominal variables the logistic regression model is very much useful. for the independent variable, the daily income of the workers, and the Covid-19 variable which is Changes in Fixed time slots of business are taken. The time slot that is available for the Street vendor is 6.00 AM to $11.00 \mathrm{AM}$ so many street vendors caring business in the evening changed to the fixed time slot available. 
Table 1- Variables and definitions

\begin{tabular}{|l|l|}
\hline \multicolumn{1}{|c|}{ Variables } & \multicolumn{1}{c|}{ Definitions } \\
\hline Personal Debt (Dependent Variable) & 1 for increase in debt, Otherwise 0 \\
\hline Fixed Slots Changes (Independent Variable) & 1 for time slot of business change, Otherwise 0 \\
\hline Mobility Restrictions (Independent Variables) & 1 for mobility restrictions, Otherwise 0 \\
\hline
\end{tabular}

\section{ANALYSIS AND DISCUSSION OF RESULT}

Table 2- Logistic Regression Result

Dependent Variable:CHANGE_IN_PERSONAL_DEBT_LEVEL

Method: ML - Binary Logit (Newton-Raphson / Marquardt steps)

Sample: 1105

Included observations: 105

Convergence achieved after 4 iterations

Coefficient covariance computed using observed Hessian

\begin{tabular}{llcc}
\hline \hline Variable & Coefficient & Std. Error & z-Statistic \\
\hline \hline FIXED_TIME_SLOT_CHANGES & -2.950123 & 0.811741 & -3.634316 \\
MOBILITY_RESTRICTION & -1.730758 & 0.805461 & -2.148780 \\
C & 2.624395 & 0.478178 & 5.488325 \\
\hline \hline McFadden R-squared & 0.517058 & Mean dependent var & 0.0000 \\
S.D. dependent var & 0.480003 & S.E. of regression & 0.0000 \\
Akaike info criterion & 0.683912 & Sum squared resid & 0.304600 \\
Schwarz criterion & 0.759740 & Log likelihood & 9.463708 \\
Hannan-Quinn criter. & 0.714639 & Deviance & -32.90540 \\
Restr. deviance & 136.2707 & Restr. log likelihood \\
LR statistic & 70.45990 & Avg. log likelihood \\
Prob(LR statistic) & 0.000000 & & -65.81080 \\
\hline \hline Obs with Dep=0 & 37 & Total obs & -0.313385 \\
Obs with Dep=1 & 68 & & 105 \\
\hline \hline
\end{tabular}

Table- 2 shows that the dependent variable having 0 value are 37 in numbers and the dependent variable having 1 as value are 68 in numbers, it suggests that among respondents out of 105 respondents 68 have increased in debt and 37 have not increased in debt level. the LR statistic of 70.45 and Prob (LR statistic) value of 0.00 which suggest that the Covid-19 Variable i.e. fixed time slot change and mobility restriction together affects the personal debt of street vendor significantly as probability value of LR (Likelihood Ratio) statistic which is equivalent of F-test in linear regression Model is nearly 0 . The McFadden $r$ square value of 0.51 is suggesting that the model fits well as in logistic regression the value of $\mathrm{McFadden} r$ square above 0.2 . The sign of the coefficient of both the variables such as fixed time slot changes and mobility restrictions minus (-) which suggests that if Mobility restriction falls and Fixed Time Slot changes the personal debt level of the street vendor in Rourkela will increase. The P-value of Both the variable which are 0.000 and 0.0317 suggest that individually both the variables are significantly affecting the debt level of the street vendors of the Rourkela city. Overall, the result from logistic regression shows that the personal debt of street vendors in Rourkela city does increase because of covid-19. 


\begin{tabular}{crrrrrr}
\hline \hline & $\begin{array}{c}\text { Estimated Equation } \\
\text { Dep=0 }\end{array}$ & Dep=1 & Total & Constant Probability \\
Dep=0 & Dep=1 & Total \\
\hline \hline P(Dep=1) $<=C$ & 31 & 5 & 36 & 0 & 0 & 0 \\
P(Dep=1)>C & 6 & 63 & 69 & 37 & 68 & 105 \\
Total & 37 & 68 & 105 & 37 & 68 & 105 \\
Correct & 31 & 63 & 94 & 0 & 68 & 68 \\
\% Correct & 83.78 & 92.65 & 89.52 & 0.00 & 100.00 & 64.76 \\
\% Incorrect & 16.22 & 7.35 & 10.48 & 100.00 & 0.00 & 35.24 \\
\hline \hline
\end{tabular}

Prediction Evaluation for Binary Specification from table 3 suggests that with a cut-off point of 0.5 , in the estimated equation the Correct \% is $89.52 \%$ which means out of 105 observations our model correctly predicted the outcomes 94 times. With constant probability, the model correctly predicted the outcome 68 times out of 105 observations.

\section{FINDINGS}

The objective is to study the effect of Covid-19 on the personal debt of street vendors, and it has been found that there is a significant effect of covid-19 on the personal debt of street vendors as the not only majority of the respondent lose their job during Covid-19 period but strict lockdown also affected their earnings. It is also found that the fixed time slot to do business was only limited to 4-5 hours from 6:00 AM to 11:00 AM also limited their earning and had to throw away those unsold perishable goods on which they had invested their capital.

\section{CONCLUSION}

Undoubtedly Covid-19 Pandemic severely impacted almost every sector of the economy and street vendors also didn't remain untouched. Their daily income is drastically reduced and becomes difficult to even earn for a day living. They are still fighting with Covid-19 by risking their lives just for a day earnings to support their family.. Their condition was very harsh \& pitiful, especially during the Covid-19 period. Though both central and state governments have come up with PM SVANIDHI loan and state scheme of amounting to 10000 \& 3000 respectively but 61 out of total 105 respondents are not aware of this scheme \& 98 respondent nor does avail PMSVANIDHI loan hence awareness of this scheme is needed at this time.

\section{REFERENCE}

1. Deka, B. (2020). Withstanding Covid 19 And Its Effects by Street Vendors: A Study on Their Livelihoods During Post Lockdown Phase in Guwahati City. Journal of Critical Reviews, 7(13).

2. Husain, S., Yasmin, S., \& Islam, M. (2015). Assessment of the Socioeconomic Aspects of Street Vendors in Dhaka City:
Evidence from Bangladesh. Asian Social Science, 11(26). https://doi.org/10.5539/ass.v11n26p1

3. Majithia, A., 2021. Impact of COVID-19 on Street Vendors in India: Status and Steps for Advocacy. Women in Informal Employment: Globalizing and Organizing (WIEGO).

4. Meher, S., Ranjan, A., Tamgire, L., \& Shukla, P. (2020). It is lockdown but homes are not closed. Income has been shut down but expenses continue:' Impact of lockdown due to COVID-19 on the livelihood of Street Vendors in Maharashtra. Research Square, 1-12. https://doi.org/https://doi.org/10.21203/rs.3.rs-55208/v1

5. More than 60 per cent of the world's employed population are in the informal economy. Ilo.org. (2018). Retrieved 20 November 2021, from https://www.ilo.org/global/about-theilo/newsroom/news/WCMS_627189/lang--en/index.htm.

6. Street vendors struggle to stay afloat. The Hindu. (2020). Retrieved 12 November 2021, from https://www.thehindu.com/news/cities/bangalore/streetvendors-struggle-to-stay-afloat/article31387525.ece

7. Turner, S., Langill, J. C., \& Nguyen, B. N. (2021). The utterly unforeseen livelihood shock: COVID-19 and street vendor coping mechanisms in Hanoi, Chiang Mai and Luang Prabang. Singapore Journal of Tropical Geography, 42(3), 484-504. https://doi.org/10.1111/sjtg.12396

8. Ullah, M. (2021). Livelihood of Street Vendors During Covid19 Lockdown in Bangladesh: Earnings Break off Expenses Remain. Indonesian Journal of Social Research (IJSR), 3(3), 160-170. https://doi.org/10.30997/ijsr.v3i3.142

9. Vijayarani, K., \& Selvam, S. (2021). A Comparative study on Impact of Pre and Post Covid-19 on Street Vendors in Cuddalore district. JEMR, 11(4), 1-13. 